\title{
PUBLICIDAD Y TURISMO: LA INDUSTRIA DEL FORASTERO EN LA EXPOSICIÓN REGIONAL DE VALENCIA DE 1909
}

\author{
Francesc-Andreu Martínez Gallego \\ Universitat de València \\ francesc.martinez@uv.es
}

\begin{abstract}
Resumen: El 22 de mayo de 1909 abrió sus puertas la Exposición Regional de Valencia, un gran acontecimiento para la promoción del cual se arbitraron estrategias propagandísticas que seguían las pautas de la moderna publicidad comercial. Aquí se estudian los procedimientos de promoción del evento, sus vínculos con el interés reciente por la promoción del "negocio de los forasteros", el turismo; así como sus resultados.
\end{abstract}

Palabras clave: Turismo, propaganda, publicidad, comunicación corporativa, exposiciones.

Abstract: On the 22nd May 1909 the Valencian Regional Exhibition was opened. It was a great event that was promoted by advertising strategies which followed the modern patterns of the commercial advertising on fashion. In this article we are studying the procedures used for the promotion of the event, its links with the recent interest of he "foreigner's business": tourisms well as its results.

Keywords: Tourism, propaganda, advertising, corporate communication, exhibitions.

\section{EXPOSICIÓN: LA ESTRATEGIA DEL EVENTO}

a celebración de la Exposición Regional de Valencia en 1909 coincidió con la primera fase de la intervención pública desarrollada por el gobierno español - para la atracción del turismo exterior y también con las primeras iniciativas privadas en idéntico sentido.

A través del análisis de documentación de primera mano, de archivo y hemerográfica, trataremos de someter a discusión la hipótesis según la cual la Exposición valenciana de 1909 tuvo una doble agenda: una expresa; la otra oculta. La primera, publicitaria, vinculada a la promoción del turismo y a corregir las primeras iniciativas empresariales fracasadas en esa materia; la segunda, política, propagandística, centrado sobre la promoción de las opiniones monárquicas, en especial las conservadoras, en una ciudad dominada por las republicanas.

Que la promoción turística había nacido con el siglo, es una evidencia (Correyero y Cal, 2008). Un Real Decreto de 6 de octubre de 1905 creaba una Comisión Nacional de Turismo, adscrita al Ministerio de Fomento (González Mo- 
rales, 2005). El libro La Industria de los forasteros, de Bartolomé Amengual, vio la luz en 1903 y, en 1909, el conde de Bailén daba a imprenta Las importantes ventajas que produce el desarrollo del turismo en España. Entre ambas publicaciones surgieron el Centro de Iniciativas Turísticas en San Sebastián (1903), la Sociedad de Fomento del Turismo en Palma de Mallorca (1906) o la Sociedad de Atracción de Forasteros en Barcelona (1908), como sindicatos de iniciativas turísticas. Existían, como precedentes, los Centros Excursionistas, por ejemplo el creado en Barcelona en 1890, que, además de promover desplazamientos programados para sus socios, iniciaron la práctica de la publicidad cartelística de sus actividades (Montaner Montejano, 1998).

Ya en 1906 apareció un Sindicato de Iniciativa de Valencia y su Región (ADV: Central Indeterminado, Caja 14), que no aparece citado en ninguna de las monografías que relacionan la aparición de las primeras sociedades privadas para la promoción del turismo. El Sindicato, presidido por el señor Serrano Morales e impulsado por el ex alcalde liberal Joaquín Reig Piqué, elaboró desde el principio una estrategia para encarar las tres grandes cuestiones que le preocupaban: la propaganda, los transportes y los hospedajes. Sus socios pensaban que la ciudad de Valencia partía con desventaja respecto a los grandes centros turísticos franceses, italianos e incluso españoles, porque "el estado actual de nuestra ciudad dista mucho de ser el que requiere su importancia, por haber permanecido estacionada y como petrificada durante muchos años mientras se desarrollaba la transformación de las capitales modernas".

Sin embargo, el Sindicato no obtuvo el apoyo económico de las grandes instituciones regionales, las diputaciones provinciales. Tan sólo buenas palabras. Y languideció hasta extinguirse. Quedaron, eso sí, algunos artículos en prensa que lanzaban ideas vinculadas al desarrollo turístico. Muy en especial los escritos por Alejandro Settier (véase el ejemplar del 11 de agosto de 1906 de El Mercantil Valenciano), personaje que será luego clave en la organización de la Exposición de 1909.

La causa del fracaso del Sindicato de Iniciativas no se encuentra sólo en la falta de apoyos institucionales. También merece mención el divorcio político entre los liberales que lo componían y la mayoría política republicana, tanto en el municipio como en la representación en el Congreso. La ciudad "petrificada" a la que aludía el Sindicato era una ciudad de mayoría republicana pero regida por alcaldes liberales o conservadores, según recayese en unos u otros el turno restauracionista, dado que el primer edil lo era por designación gubernamental. La parálisis política de la urbe era una de las consecuencias de esta falta de correlación entre gobernantes y gobernados. Y, por otra parte, la Diputación Provincial prefería volcar sus esfuerzos sobre las comarcas en las que funcionaban las redes clientelares, antes que sobre la ciudad que en buena medida escapaba a su influencia (Martínez y Laguna, 1995).

Mientras el Sindicato de Iniciativas de Valencia y su Región se hundía, el vínculo entre exposiciones y turismo, que venía de lejos, cobraba nuevos bríos. 
Zaragoza celebraba en 1908, y para conmemorar el centenario de la ciudad sitiada y resistente frente a las tropas napoleónicas, su particular Exposición Hispano-Francesa, a la cual asistió más de medio millón de visitantes (Blanco García, 2007). Promovida, entre otros, por Basilio Paraíso, que presidió el comité ejecutivo organizador, la exposición se nutrió con el aroma del regeneracionismo en boga y sirvió de marco para diversos congresos, entre los cuales cabe destacar el Primer Congreso Internacional de Turismo y de los Sindicatos de Iniciativa (Bayón y Fernández, 2005).

Una de las secciones de dicho congreso se dedicó a los mecanismos de publicidad y propaganda que debían acompañar la promoción turística e intentó estimular la realización de guías de viajeros en diversos idiomas, así como la realización de catálogos de monumentos, estaciones estivales e invernales, balnearios o alojamientos. Los Sindicatos de Iniciativas turísticas debían promover guías y catálogos, pero también gestionar ante los poderes públicos las necesarias facilidades para la movilidad y la estancia de los forasteros interesados por el turismo (Moreno Garrido, 2007). Como se recordará, nada que no hubiese lanzado ya el malversado Sindicato de Iniciativas de Valencia y su Región.

Las conclusiones del Primer Congreso Internacional de Turismo incidían sobre el Real Decreto que tres años antes había deparado la constitución de una Comisión Nacional de Turismo y que en su articulado preveía divulgar en el extranjero los monumentos y paisajes españoles mediante la confección de itinerarios y guías de viajes, gestionar con las compañías ferroviarias sistemas tarifarios atractivos para el público extranjero o concertar con diputaciones y ayuntamientos la mejora de los alojamientos.

Sin duda, la necesidad de insistir sobre los términos legislados es indicativo de que las iniciativas de la Comisión Nacional de Turismo caminaban a paso lento y de que los sindicatos de iniciativa turística estaban columbrando el enorme potencial económico que significaba la industria de los forasteros y se impacientaban ante la inacción gubernamental en la materia (Vidal Casellas, 2005).

Por otra parte, mientras los documentos que las primeras iniciativas turísticas sacaban a la luz hablaban de la confección de guías y de la orientación del turismo hacia itinerarios vinculados a monumentos, playas, balnearios, paisajes notables, reales sitios o estaciones invernales, las prácticas se orientaban más bien a la organización de grandes acontecimientos. Las exposiciones lo eran. Lo viejo y lo nuevo se mezclan.

Sin duda, la concepción del viaje turístico se estaba transformando y su perfil contenía elementos del pasado e innovaciones que, ahora lo sabemos, contaban con futuro. Las prácticas turísticas burguesas decimonónicas, vinculadas a las estancias en balnearios, al "tour" por las grandes capitales o al viaje para la contemplación de monumentos singulares, habían generado materiales de promoción: publicaciones tales como las Guías de Forasteros y similares. 
A partir de la década de 1840 estas guías son harto frecuentes en las ciudades españolas y hasta, en algún caso, se publican en dos lenguas, el castellano y el francés: la Guía del Viajero en Valencia, publicada en 1866 por José María Settier, es un ejemplo; además de localizar los principales hitos turísticos de la ciudad, proponía al viajero una serie de excursiones a los alrededores de la urbe para explorar paisajes, monumentos u obras de interés (Serna y Pons, 2004).

Sin embargo, en 1900, como apunta Uría (2003), se está produciendo la emergencia de nuevas formas de consumo y bienes de ocio que inciden sobre la erosión paulatina de la vieja cultura tradicional de los sectores populares, que erigen verdaderas industrias culturales y que facilitan procesos de integración en el espacio del ocio mercantilizado de las clases populares. Ello no significa, claro, que el turismo se extienda hacia sectores ni siquiera mesocráticos de la sociedad española de entresiglos, pero sí supone que muchas de las actividades -del estilo de los parques de atracciones o las competiciones deportivas- tiendan a activar la presencia de públicos interclasistas. Sin duda, las exposiciones regionales, nacionales o universales eran momentos apropiados para el desarrollo de grandes montajes de ocio, para el establecimiento de prácticas venales relacionadas con las que, adicionalmente, podían apartar a las clases populares de prácticas consideradas inmorales por parte de la burguesía de la época, tales como la taberna, determinado teatro o fiestas carnavalescas (Erice, 2003).

Si el ocio, poco a poco, entraba en la senda de la mercantilización, de la integración interclasista y de la industria cultural, el turismo, uno de sus componentes, podía ser vanguardia de esta transformación. Y una Exposición Regional, como la valenciana de 1909, podía subsumir ambos elementos, a condición de que el hecho fuese suficientemente conocido y difundido.

Cuando el principal impulsor de la Exposición, Tomás Trenor Palavicino, presidente del Ateneo Mercantil de Valencia, se puso en contacto con el presidente de la Cámara de Comercio, Industria y Navegación de Valencia, Ramón de Castro, para aunar esfuerzos, éste estableció un conjunto de tareas a las que la Exposición debía servir: la construcción del ferrocarril directo entre Madrid y Valencia, la terminación de las obras del puerto y su inclusión en las líneas de intercomunicación con el norte de África, norte de Europa, sur de América y Extremo Oriente, el establecimiento de tratados comerciales con diversos países, la organización de nuevas vías de exportación, la fundación en la Universidad de estudios de economía y geografía comercial y "fomentar el turismo en cuanto a esta región beneficie" (AHCCINV, H-187/07).

Este es un aspecto no divulgado de la Exposición de 1909, que de Regional pasó a ser Nacional en 1910. Se ha hablado del cambio de imagen que para Valencia representó la Exposición al centrarse, sobre todo, en productos manufacturados, esto es, al convertirse en un gran escaparate de la industrialización (Boira, 2009). Aunque la economía valenciana era predominantemente agraria, el crecimiento de las manufacturas había llevado a la región a situarse la tercera 
en el ranking industrial español, solo por detrás de Cataluña y el País Vasco (Martínez Gallego, 1995). Se ha hablado del impacto de la Exposición sobre el planeamiento urbanístico y sobre la dimensión arquitectónica de la ciudad (Vegas, 2003). Se han tocado otros aspectos del acontecimiento, pero su concepción de atractivo turístico, de vínculo entre el gran acontecimiento expositivo y las iniciativas para reorientar formas de ocio queda todavía velada. Intentemos, pues, una aproximación.

\section{LA NUEVA PROPAGANDA}

El término propaganda no tenía en 1909 las connotaciones peyorativas con las que se fue cargando con el paso del tiempo; tampoco tenía una caracterización tan precisa que permitiese separarla de la publicidad. De ahí que los organizadores de la Exposición Regional Valenciana se dotasen de una Secretaría de Propaganda, dirigida por Alejandro Settier, el mismo que tres años antes había intentado dar eco periodístico al Sindicato de Iniciativas turísticas.

Mirándose en el espejo de la exitosa Exposición Hispano-Francesa de Zaragoza de 1908, la de Valencia aspiraba también a congregar gran cantidad de público y a convertirse en noticia atractiva en las redacciones de periódicos españoles y foráneos. Propaganda, en el vocabulario del turismo, era equivalente a creación de demanda (Cal, 1997). Todavía no existía la sutileza de diferenciar la propaganda y la publicidad, ambas encaradas a influir sobre las conductas sociales, en función de la búsqueda de provecho ideológico en un caso y de lucro en el otro (Pineda, 2006).

La pretensión, en todo caso, había que materializarla con esfuerzo y con presupuesto. Sobre un total de gastos que ascendió a seis millones de pesetas, el apartado destinado a propaganda se computó en casi doscientas mil (Trenor, 1912). Es obvio que la cantidad, a vista de hoy, puede parecer escasa. Pero conviene recordar que se trata de una iniciativa pionera.

En 1909 la comunicación publicitaria está todavía en fase incipiente de desarrollo. Aunque la mayor parte de las grandes ciudades españolas cuentan ya con agencias de publicidad, se trata de pequeñas empresas dedicadas básicamente a intermediar entre anunciantes y prensa. Pedro Prat Gaballí, el gran teórico de la moderna publicidad, no impartió su famoso curso sobre la cuestión, en el que hablaba precisamente de la necesidad de destinar presupuesto a la propaganda comercial por parte de las empresas, hasta 1915 (Barjau, 2002).

Para los teóricos de principios del siglo XX, la propaganda era el mecanismo por el cual se diseminan las ideas a gran escala. Lectores, en muchos casos, de Gustave Le Bon (su La psychologie des foules, de 1895, fue vertido al castellano al año siguiente) estaban convencidos de que el grupo posee características "mentales" distintas del individuo: se mueve por impulsos, hábitos, emociones. Por ende, domeñar hábitos y emociones colectivos era el nuevo paradigma (Bernays, 
2008). Desde finales del siglo XIX la publicidad comercial parecía seguir estos principios: del mismo modo que el jabón Heno de Pravia (de la casa Gal) vinculaba el producto a sensaciones como el frescor, o Bibendum, el célebre muñeco que Michelín echó a rodar en 1898, se convertía en la primera gran imagen de marca, era posible que la Exposición encontrase los resortes de comunicación que llegasen a las emociones de un público potencialmente expectante.

El Secretario de Propaganda de la Comisión Ejecutiva, Alejandro Settier, era el descendiente de una afamada familia local vinculada a la industria y a la promoción de la ciudad o, si se quiere, a la "industria del forastero". La saga la inició un inmigrante italiano, Baltasar Settier Gobeto que llegado a Valencia en la década de 1820, contaba con la mayor fábrica de sombreros de la región a mediados de la centuria. De uno de sus hijos, José María Settier, ya se ha hablado aquí y precisamente como autor de una de las más importantes guías de viajeros en Valencia, la editada en 1866. Nuestro Alejandro Settier Aguilar nació en 1858. Era, pues, hombre de la tercera generación de aquellos turineses que habían llegado a Valencia en busca de fortuna y que, sin duda, la hallaron.

Alejandro cursó el bachillerato en el colegio de los Jesuitas y estudió la carrera de medicina, licenciándose en 1880. Amplió estudios en París, especializándose en enfermedades de las vías genito-urinarias. De regreso, abrió una clínica en Madrid y fundó la revista Progreso Médico-Farmacéutico. En la década de 1880 dio a la imprenta una gran cantidad de obras de carácter médico, que supusieron un considerable avance para la puesta al día de su especialidad, la urología, en España.

Sin embargo, en la década siguiente, tras perder a sus dos hijas, abatido por la circunstancia, Settier regresó a Valencia y se desvinculó de la medicina, dedicándose a participar en los debates regeneracionistas en boga, siempre desde la perspectiva de un cierto regionalismo valenciano. Publicó centenares de artículos en El Mercantil Valenciano, Las Provincias y algún que otro diario madrileño. Editó en folletos recopilaciones de una porción de tales artículos: así La descentralización administrativa y los conciertos económicos (1907) recogía los que habían hecho campaña contra la excesiva centralización, o La instrucción pública en España: una vergüenza nacional (1911), aquellos otros dedicados a poner en jaque el sistema educativo del país.

Entre la publicación de los dos opúsculos citados, dedicó buena parte de sus trabajos periodísticos a reclamar la construcción de un ferrocarril directo de Valencia a Madrid y, cuando surgió la idea de la Exposición, fue de los primeros en secundarla en campaña periodística. Nombrado Secretario de Propaganda de la Exposición, compuso una Guía y Catálogo Oficial de la Exposición Regional de Valencia, con la que proseguía una tarea que en el siglo anterior también había recaído en su familia (Obiol Menero, 1999).

La Guía de Alejandro Settier ofrecía en su primera parte una orientación al forastero sobre los atractivos y las rutas turísticas que podía encontrar en Valencia 
y sus alrededores. Por ende, se ha destacado su vocación de promoción turística. Pero, además, la Guía de Settier sirvió de base para la edición de otras guías vinculadas a algunos de los congresos que se iban a celebrar en el recinto de la Exposición Regional o a editores privados de la ciudad que aprovechaban el evento para sacar a la calle un material con seguro mercado si el evento alcanzaba las previsiones de público asistente que se barajaban: así por ejemplo, la Guía de Valencia costeada por la Asociación Española para el Progreso de las Ciencias.

Pero la tarea de Settier superó con mucho la mera realización de la Guía. Fue el responsable del establecimiento de una estrategia promocional de la exposición. No partía de la nada. Conocía las ideas abortadas del Sindicato de Iniciativas local. Y conocía los debates del primer Congreso Internacional de Turismo, celebrado en Zaragoza en noviembre de 1908, dónde se habían propuesto nuevas estrategias de atracción de turistas (Pamplona, 1908).

Settier proyectó una estrategia publicitaria -seguía llamándola propagandística- en dos fases y concibió una serie de soportes publicitarios y de destinos de los impactos que pretendían cubrir tanto el flanco del turismo interior como el del exterior.

\section{LAS OLEADAS: ESTRATEGIAS DE PROMOCIÓN}

La prensa, el cartel, los carnés-prospecto, los programas de mano y los planos del recinto expositivo serán los soportes fundamentales de la publicidad de la Exposición Regional de Valencia. Se trataba de procedimientos "a la moderna"; tanto que el mismo Trenor escribió que con ellos "entrábamos en las costumbres de los pueblos grandes usando para competir con ellos sus mismas armas y recursos". ¿Exageraba? La prensa, sin duda, era un soporte tradicional de la publicidad, pero la gran cartelística de la belle époque había adquirido auge tan sólo quince años antes. La conversión de los carnés, los programas de mano y los planos en soportes publicitarios eran recursos que, auque existían, venían utilizándose como soporte informativo en determinados espectáculos, pero no como elemento publicitario masivo. Sin duda, la novedad existía.

Esta era, pues, la vertiente masiva de la Exposición: los recursos para atraer a centenares de miles de visitantes, tal y como se había propuesto el Comité Ejecutivo. La Secretaría de Propaganda concibió dos grandes oleadas o campañas publicitarias (AHCCINV, H-187/07): una a realizar en los meses previos a la Exposición, desde enero de 1909; la otra en julio, cuando la Exposición llevaba dos meses abierta y se planteó reforzar las llamadas a la asistencia, especialmente de forasteros, en el tramo final del evento. 
Cuadro 1. Oleadas publicitarias de la Exposición Regional de Valencia.

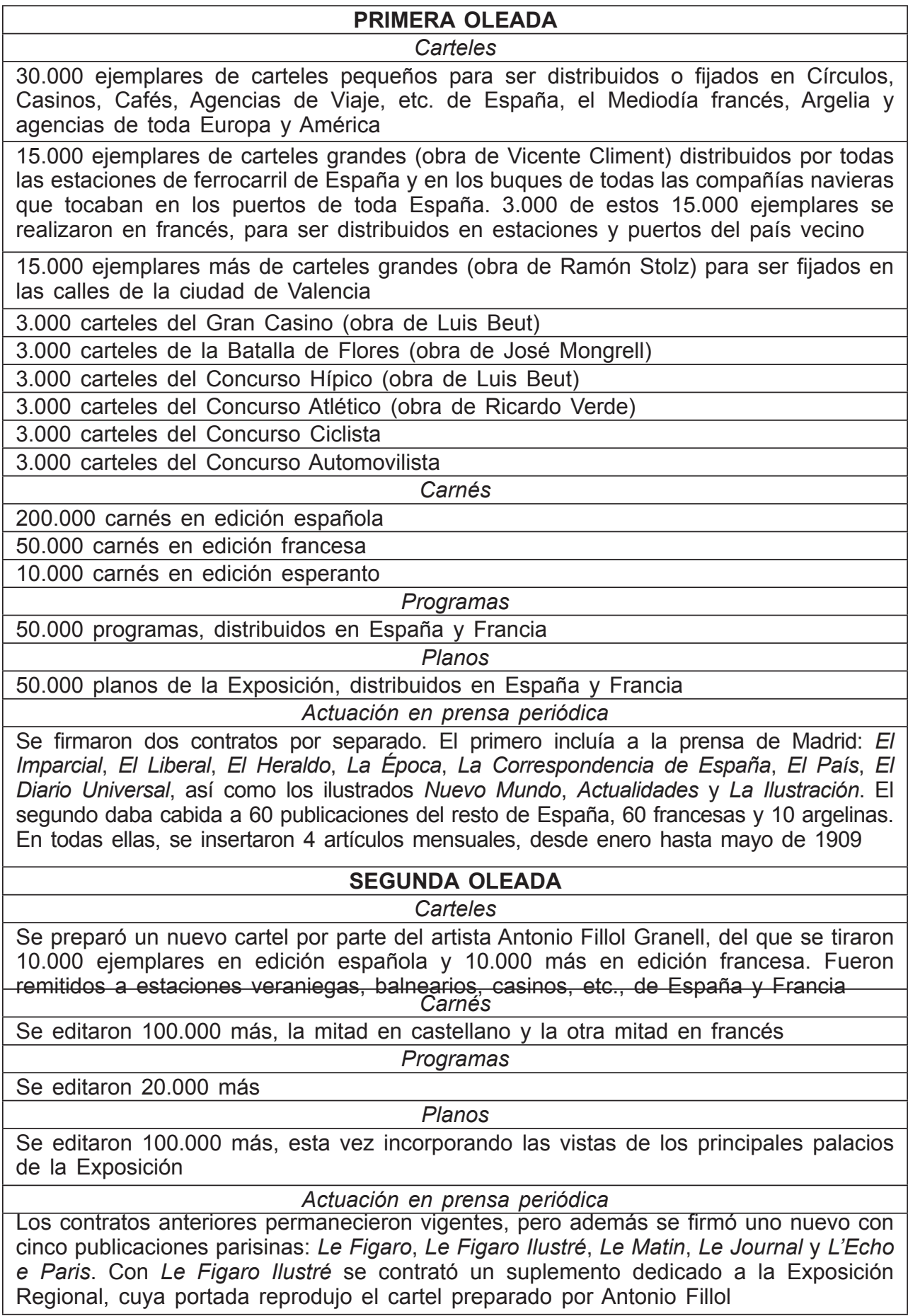

Fuente: Elaboración propia. 
Sin duda, Settier y sus colaboradores vincularon estrechamente el impulso de la Exposición al potencial turístico de futuro. Al fin y al cabo, ya el Sindicato de Iniciativas en 1906 había explicado que había mucho dinero que ganar si se atraía a esa "inmensa ola de excursionistas procedentes del Norte de Europa y América que invaden los países del Sur dejando en pos de si una estela de billetes de banco que recogen las regiones que, concientes de las necesidades de su tiempo, han sabido hacer valer sus riquezas artísticas, históricas y naturales" (ADV: Central-Intederminado, caja 14). Por su parte, Tomás Trenor, en su Memoria de la exposición (1912), destacó esta cuestión: se pretendía que la Exposición fuese visitada por "un centenar de millares de turistas [...] que se encargarían de fomentar la concurrencia en los años venideros".

Para el presidente de la Comisión Ejecutiva resultaba esencial mostrar que "en España hay algo más que las procesiones de la Semana Santa sevillana y las corridas de la Feria de la ciudad del Betis; algo más que la Alhambra y el Escorial y Toledo [...]. Valencia brinda en todo tiempo atractivos singulares y ocasiones de convencerse [...] de que nada envidia a los países tenidos como obligada estancia para los adinerados ganosos de cosas nuevas y agradables".

Como es fácil detectar en los impactos buscados por las dos oleadas publicitarias de la Exposición, el turismo francés era el más buscado, viniese de la misma Francia o de su colonia argelina. Y, de hecho, los contactos directos con Argel dieron sus frutos, puesto que el gobernador francés en aquella ciudad declaraba en abril de 1909 que Valencia había iniciado su renacimiento "que la conducirá rápidamente a colocarse al nivel de las mejores ciudades europeas (Las Provincias, 29/4/1909).

Argelia, colonia francesa desde 1830, tenía un vínculo muy especial con el País Valenciano. Del censo realizado en 1896 en la ciudad de Orán se desprendía la existencia de casi 300.000 europeos residentes, de los que 100.000 eran españoles y otros 100.000 franceses aunque de origen español. De los 524.248 europeos nacidos en Argelia, en torno al 40 por ciento era de origen español y habitaban fundamentalmente en las ciudades de Argel, Orán y Constantina.

Un inspector de emigración explicaba por entonces que "Argelia no es para los españoles, como para los franceses, una tierra lejana. Vienen sin aprensión. No hay que sentirlo, porque los obreros duros y sobrios para el trabajo que enviaron las provincias de Valencia, Alicante y Almería constituyeron el éxito de la agricultura de la región. Estos obreros son excelentes, sobre todo en la huerta". En efecto, en las zonas de cultivo del occidente argelino se hablaba con frecuencia en valenciano, las compañías teatrales peninsulares incluían a la ciudad de Orán en sus giras y hasta algunos periodistas que huían de España por razones casi siempre políticas, editaban allí periódicos en castellano (Vilar, 1975).

Así pues, valencianos y alicantinos habían protagonizado una intensa migración laboral, creando una amplia colonia de residentes en Argelia, alguno de cuyos miembros volvía cuando podía a su país o, habiendo fijado su residencia 
de forma definitiva en la colonia francesa, soñaba con retornos siquiera esporádicos. Los organizadores de la Exposición pretendían aprovechar este hecho. Españoles nacionalizados franceses, franceses hijos de españoles, franceses con conocimiento, por contacto frecuente, con la cultura española y específicamente valenciana, eran un enorme potencial de visitantes, de turistas.

Francia, en especial el Mediodía francés, era también espacio codiciado por la publicidad de la Exposición. En este caso, el factor migratorio no tenía la misma relevancia que con respecto a las ciudades argelinas. Entre 1880 y 1914 emigraron cerca de 5 millones de españoles, pero los destinos preferentes fueron América, muy por delante, y África. La emigración a Francia, aunque se intensificó a partir de 1914, fue escasa hasta esa fecha. Sin embargo, lo que existía con respecto al Mediodía francés eran contactos longevos tanto de naturaleza comercial como cultural. Importa, por ejemplo, recordar, que buena parte del vino valenciano se exportaba al sur francés para ser allí elaborado. Por otra parte, desde mediados del siglo XIX, los contactos culturales vinculados a la renaixença, al renacimiento de la literatura vernácula, habían proliferado, dada la cercanía lingüística entre la lengua Occitana y las diferentes variantes dialectales del catalán. Los contactos entre literatos, las visitas frecuentes con motivo de Juegos Florales u otros certámenes literarios, podían ahora, en 1909, servir de palanca y reclamo a la visita turística.

Como se recordará, los carteles debían distribuirse en círculos, casinos, cafés y agencias de viaje no sólo francesas y argelinas, sino también españolas, europeas y hasta americanas. Ciertamente, se tenía poca confianza en el potencial contingente de visitantes europeos (no franceses) o americanos. Para ellos Valencia seguía siendo un destino lejano y caro. Sólo alguno de los congresos que se iba a celebrar con motivo de la Exposición podía atraer a algún sabio forastero, pero esta era una cuestión menor.

En el ámbito español había más esperanzas. Pero también una dificultad objetiva: aunque hacía unos años que se reivindicaba el tren directo de Valencia a Madrid, lo cierto es que no existía y que las comunicaciones con el resto de la península no eran particularmente buenas. El tren a Madrid recorría 490 kilómetros y pasaba por la estación de enlace de La Encina. Era un largo viaje, y caro (61,65 pesetas en primera clase, 28,75 en tercera). De hecho, el viaje tenía menor recorrido, 440 kilómetros si se efectuaba vía Aragón, tocando Teruel y Calatayud, aunque también era pesado y costoso. Los dineros gastados en publicitar la Exposición en la prensa madrileña podían tener, pues, un efecto limitado sobre la concurrencia de capitalinos a la Exposición.

La salvedad en cuanto a comunicaciones la representaban Cataluña y las Baleares. Desde finales de la década de 1860 Valencia y Barcelona estaban conectadas por ferrocarril; la línea de 366 kilómetros conectaba además ciudades relevantes, como Sagunto, Castellón y Tarragona. Además, como con los puertos de Marsella o Cette, el de Valencia estaba bien relacionado con el de Barcelona, existiendo dos compañías -la Compañía Valenciana de Navegación y la Com- 
pañía Cola y Maycas- que cubrían trayectos directos cuatro veces por semana. También el puerto de Valencia y el de Palma de Mallorca estaban bien relacionados: un vapor correo, que hacía escala en Ibiza, viajaba todos los viernes.

De modo que catalanes y mallorquines eran los principales objetivos de la publicidad de la Exposición y, desde luego, los considerados como el mayor potencial turístico en el futuro inmediato. De hecho, la Exposición programó varios actos en los que catalanes y mallorquines tuvieron protagonismo. En el ámbito musical, el Orfeó Catalá fue una de las grandes atracciones; como en materia de coros y danzas lo fueron las danzas folclóricas mallorquinas. El periódico marroquín La Última Hora organizó viajes entre sus suscriptores para visitar la Exposición (Valencia, 25/7/09).

No es cierto, aunque así lo indique la Memoria redactada a posteriori por Trenor, que se pretendiese, sólo, la concurrencia de un centenar de miles de visitantes turistas. Lógicamente, la Memoria se redactó tras el acontecimiento e intentó conciliar las presuntas expectativas iniciales con sus resultados reales. Sin embargo, los cálculos de visitantes previstos realizados en los prolegómenos de aquel 22 de mayo de 1909, día en el que se inauguró la Exposición, apuntaban más alto. A emular la cantidad de visitantes que recibió la Exposición zaragozana del año anterior: el medio millón de visitantes era el listón. La Memoria rebajaba post hoc las expectativas. Por tanto, los objetivos propuestos en las oleadas publicitarias no se cumplieron.

El contratiempo, que intentaremos explicar, no empaña necesariamente la novedad de la estrategia publicitaria y hasta su cualidad. De hecho, ésta consistía en conciliar las oleadas propagandísticas con los espacios de ocio y los acontecimientos espectaculares propuestos por la Exposición. No hay más que ver la orientación de la cartelística, su vínculo con los elementos de la modernidad del momento: el ciclismo -en 1909 se celebró el primer Giro de Italia y el Tour de Francia andaba por su séptima edición-, el automovilismo o el atletismo.

Tan masiva fue la primera oleada que muchos empresarios y contratistas extranjeros pensaron que se trataba de una Exposición Internacional y escribieron al comité organizador para ofrecer sus servicios, instalaciones o espectáculos. La idea de que la exposición valenciana iba a convertirse en epicentro de la modernidad ligada a la velocidad, a la electricidad y al ocio quedó bien afirmada desde el principio (Gil y Millán, 2009).

\section{ESPECTÁCULO DE MASAS}

En los 233 días que la Exposición estuvo abierta se celebraron 22 festivales, 21 concursos, 17 congresos, 5 asambleas, 12 conferencias, 9 sesiones de experiencias agrícolas, 96 sesiones de fuegos artificiales, 11 espectáculos en el Teatro-Circo, 45 fiestas en el Gran Casino, la mayoría bailes y cotillones, 75 audiciones musicales, 15 exhibiciones aeronáuticas, 12 "actos de diversiones varias", 
básicamente bailes populares, 22 banquetes, 3 fiestas escolares y 3 sesiones de reparto de premios.

En los 164.000 metros cuadrados que ocupaba la Exposición, la arquitectura se concibió como elemento de atracción: edificios de estilo moderno y una gran cantidad de elementos adicionales, muchos de ellos vinculados a la diversión. El arco de entrada estaba iluminado por 24 focos y 2.500 bombillas, en el momento en el que la luz eléctrica era todavía una novedad; la Fuente Luminosa, en la parte posterior del recinto, ofrecía a determinadas horas un espectáculo combinado de agua y luz de notoria dificultad técnica; la Gran Pista conformaba un auténtico estadio de grandes dimensiones; la montaña rusa Los Urales se elevaba catorce metros sobre las cabezas de los visitantes; el Tapis Roulant era una gran cinta transportadora que conducía a la primera planta del Palacio de la Industria; un Tranvía Aéreo -una especie de teleférico construido en hierro y acero- trasladaba a los visitantes al otro lado del río.

La Exposición estaba concebida, en su conjunto, como un espectáculo permanente, con capacidad para proponer de forma continua actividades diversas que hiciesen más grata la visita a los pabellones expositores, pero también con la intención de penetrar en las formas de ocio propuestas por los parques de atracciones. La Exposición Universal de Chicago de 1893 había creado el modelo: juegos mecánicos para estimular la visita. Y, a continuación, ciudades como Copenhague o Viena establecieron parques de atracciones permanentes, con gran éxito como puntos de comercialización del ocio. La pauta estaba servida.

Pero, como se indicó, los vaticinios no siempre se correspondieron con la realidad. La Secretaría de Propaganda escribió un informe, en el mes de julio de 1909, para trasladarlo a la Cámara de Comercio de Valencia, en el que afirmaba (AHCCINV, leg. $\mathrm{H}-187 / 08$ ):

La afluencia de forasteros ha sido hasta ahora muy variable. La más importante ha sido durante el mes de Mayo, con motivo de la inauguración de la Exposición, la venida de los monarcas y príncipes, de las Embajadas francesa, inglesa, italiana y española. De todo el Mediodía de Francia hay constantemente buen número de visitantes a pesar de las dificultades que ofrece el viaje por falta de billetes económicos y directos. Argelia está dando un gran contingente de visitantes, pues hasta ahora han venido ya 3 excursiones colectivas organizadas por casas de Orán y Argel. La que menos ha comprendido 400 visitantes. El contingente mayor de extranjeros será en Septiembre, Octubre y Noviembre, sobre todo si hay billetes económicos desde las estaciones francesas. El número de entradas vendidas en la Exposición hasta ahora, en los dos meses que lleva aquella abierta es de 400.000. [...]. No está aun confeccionado el Programa para los meses de Septiembre, Octubre y Noviembre. Pero desde luego habrá varias corridas de toros, un torneo, carreras, concursos, bailes de todas las regiones de España, etc.

El problema de los billetes de transporte $-\mathrm{y}$ de la carencia de infraestructuras viarias- no era el único. Los organizadores de la Exposición estaban preocupados porque la ciudad de Valencia no contaba con alojamientos suficientes para 
el número de visitantes que se esperaba. Valencia contaba en 1909 con 1.313 habitaciones y 1.785 camas, sumando las de hoteles, pensiones y fondas. Cifra corta si, por ejemplo, se compara con la de Zaragoza que, para su Exposición de 1908 , ofrecía 2.575 habitaciones y 3.499 camas.

Sea como fuere, las 400.000 entradas vendidas en los meses iniciales de la Exposición hacían augurar buenas expectativas, aunque eran un tanto engañosas: la mayor parte de las entradas habían sido adquiridas por el público local y de los alrededores de Valencia que acudió a la novedad con interés. Pero la "industria del forastero" no acababa de despegar. Finalmente, los meses que se supusieron como de mayor afluencia, los de finales de año, no cumplieron con los pronósticos.

El fracaso de la llegada de visitantes en los meses de octubre a diciembre lo era también de la promoción de Valencia como "estación invernal":

Tiene Valencia -decía una Guía confeccionada para la Exposición (1909)- un tesoro del que apenas se aprovecha, una inmensa riqueza sin explotar: el clima, la invernada. [...] Para el invernante, sano o enfermo, cansado por la enfermedad o por la labor en otros países fríos, ofrece Valencia sobrados medios para realizar el género de vida a que se aspire. Vida de urbe, y urbe cuyo carácter alegre lo revelan sus innumerables fiestas, una de las cuales, la Batalla de flores, no tiene rival en el mundo; urbe de cuya capacidad para el arte y para la alegría creemos da prueba la actual Exposición; vida de campo no sólo en sus espléndidos alrededores cuajados de chalets, sino en los lindos pueblecitos comarcanos unidos por trenes y tranvías de constante circulación; vida marítima, en el Grao y Cabañal, barrios hoy de la ciudad; vida excursionista y cinegética, en nuestras cercanas montañas, en tan históricas poblaciones como Sagunto y el Puig, o en la Albufera, hermosísimo lago, verdadera mina cuya explotación turística rendiría más que los suizos; todas las variadas aspiraciones que tenga el invernante de la Côte d'Azur francesa, en las costas italianas o argelinas, la podrá realizar aquí más y mejor.

El verano de 1909 fue socialmente "caliente" y dejó enormes secuelas. La Semana Trágica de Barcelona retrajo a los posibles visitantes catalanes, pero además el hecho que la desencadenó, la guerra del Rif, produjo efectos similares en otras capitales, sin ir más lejos en la propia Valencia. Todo ello "alejó a los forasteros, preocupó al país y detuvo por millares a los viajeros de todas partes de España" (Obiol Menero, 1999).

El turismo internacional afluyó a la Exposición preveniente, en lo fundamental, del Mediodía francés y de Argelia, aunque también hubo pequeños contingentes ingleses y alemanes. Por lo que respecta al turismo español, Cataluña y Mallorca fueron los lugares que proporcionaron mayor número de visitantes. La máxima afluencia se consiguió en dos jornadas, la inaugural y la del 6 de junio, con 30.207 visitantes.

Los organizadores de la Exposición, aunque no cubrieron los propósitos iniciales, estructuraron el evento en cuatro niveles y siempre con la intención de que resultase especialmente atractivo para el visitante masivo: en primer lugar, como 
un recinto expositivo; a continuación como un parque de atracciones, como un recinto para espectáculos y como un foro en el que asociaciones de distinto tipo pudiesen celebrar sus cónclaves.

\subsection{Recinto expositivo}

El certamen quiso ver representados a todos los sectores de actividad, aunque seguramente la mayor de las apuestas se decantó hacia la industria. El Palacio de la Industria se ubicó en la Fábrica de Tabacos de la ciudad, recién acabada. Obra de ladrillo visto con zócalos de piedra calcárea, de estilo neoclásico, muy sobrio y funcional, firmada por los arquitectos Celestino Aranguren y Ramón Lucini, la fábrica fue cedida por la Compañía Arrendataria de Tabacos al Ateneo Mercantil para albergar la muestra expositiva y sólo a partir de 1911 pudo cumplir con el cometido para el que había sido proyectado (Teixidor y Hernández, 2000). El edificio de dos plantas albergó, en la primera, los productos de las muchas fábricas de loza, azulejos y cerámicas, así como la construcción de carros y guarniciones, los carruajes, los aparatos eléctricos, las máquinas de coser, los licores, las industrias de la construcción (porlands, mármoles, cementos, maderas), etc. La segunda planta albergó la industria del mueble, la papelera, la juguetera, la alimentaria y la textil y marroquinera. Pero, además, en el Palacio de la Industria hubo una apuesta por la más estricta modernidad: el ingeniero Enrique Sanchis Tarazona presentó dos automóviles "en los que ha conseguido tal simplificación en el mecanismo, que le permiten venderlos en condiciones económicas que parecen inverosímiles", así como un aeroplano ligero.

\subsection{Parque de atracciones}

La Exposición había reservado una serie de espacios para el ocio de los visitantes. El evento se concibió como una gran feria: "Verbenas repetidas, tal es el éxito que alcanzaron; cotillones magníficos, frecuentes y concurridos; bailes diarios, castillos de fuegos artificiales todas las noches, conciertos por nuestra Banda Municipal, numerosos espectáculos deportivos, luz, alegría, continuo charloteo...Todas estas cosas un día tras otro" (Valencia, 1/8/09).

Lo fundamental era sorprender. Destacaban como atracciones el gran tobogán denominado La Glissoire Roulant, de 26 metros de altura y 93 de recorrido y la montaña rusa Los Urales, construida en los talleres de La Maquinista Valenciana propiedad de Francisco Climent. Importa decir que, a partir de 1900, cada ciudad europea quiso tener su Luna-Park, su Prater o su Tívoli y que, como ha escrito Dugast (2003), "las aplicaciones técnicas de la electricidad hacían posible la metamorfosis de esas concentraciones populares en verdaderas fiestas de luz". Luz, emoción, vértigo, vistas, se convertían así, ahora en Valencia, en los componentes de las nuevas formas de ocio comercializado de la era industrial.

\subsection{Recinto para espectáculos}

Conviene destacar la proliferación de los concursos. La cartelística de la Exposición nos advierte sobre aquellos que se pretendieron potenciar de manera 
especial: los deportivos. Los hubo de hípica, de vela, de atletismo, de ciclismo, de automovilismo, de tiro de pichón. Como ha escrito Carles Sirera (2008), el fútbol, aunque también estuvo presente en forma de torneo en la Exposición (enclavado entre los Juegos Atléticos), no era por entonces, todavía, el deporte rey. Si bien la hípica y el atletismo podían tenerse como deportes clásicos, el primero de vínculo aristocrático, el segundo de propensión más popular, el ciclismo y el automovilismo eran rasgos genuinos de modernidad. El primer Tour de France se había celebrado en 1903 y el Giro de Italia comenzaba el mismo año de la Exposición Regional. La primera Guía Michelín, que quiso dar consejos e información turística a los primeros conductores de coches que circulaban por Francia, se editó en 1900. La industria de la bicicleta, como la del automóvil, basó su desarrollo en el éxito de las grandes competiciones deportivas y en sus apoyos publicitarios.

La cartelística sportiva -como todavía se escribía por entonces-, como el género publicitario mismo, debía mucho a la fiesta taurina. La Exposición se celebraba no muy lejos de la plaza de toros de Valencia, por entonces la mayor en aforo del país. La Feria de Julio, tradicional reunión taurina valenciana, no pasaba por sus mejores momentos en cuanto a cartel y se decidió que la Exposición debía servir para relanzarla. Los diestros Ricardo Torres 'Bombita', Castor Ibarra 'Cocherito de Bilbao' y Rafael Gómez 'Gallo', lidiando toros de las ganaderías de Campos Varela, Concha Sierra, del marqués de Guadalest y de Miura, iban a ser los encargados de devolver prestigio a la Feria y, sobre todo, de convertirla en un atractivo turístico señero de la Exposición. Sin embargo, las cosas se torcieron y "sufrieron los aficionados una tremenda decepción, porque de los 26 toros lidiados, sólo uno de la ganadería de Concha Sierra mereció la nota de notable" (Valencia, 1/8/09). Tampoco los diestros estuvieron a la altura, además de producirse muchos cambios de última hora en el cartel.

En el Gran Casino se celebró concurso de bellezas valencianas. Rezaba su publicidad que las bases del concurso "respondían a un amplio espíritu democrático". Lo mismo podía ser admitida la hija del marqués que la del labrador de la huerta, con la condición de tener entre 15 y 25 años, no ser "belleza profesional" y, claro, ser valenciana (Valencia, 20/5/09). El espíritu democrático no sólo transpiraba en la condición de clase de las participantes, sino también en el procedimiento de elección: el público que entraba en el Gran Casino de la Exposición adquiría el derecho a votar a las bellezas, a partir de la contemplación de sus fotografías de gran tamaño $(150 \times 140 \mathrm{~cm})$.

Se presentaron ochenta y tres chicas, aunque se hizo una selección en la que sólo seis pasaron a la "final". El premio mayor, 5.000 pesetas, se acompañaba del honor de ser presentada al rey de España el día que éste visitase la Exposición. Conviene recordar que el primer gran concurso de belleza a la moderna se celebró en Atlantic City en 1921, cuando se eligió por vez primera a Miss Estados Unidos. Sin embargo, desde la década de 1880 los concursos de belleza femeninos estaban siendo patrocinados por algunos periódicos que 
buscaban estrategias de atracción de nuevos públicos lectores y de ese modo incrementar las ventas.

La primera Miss España, la valenciana Pepita Samper, elegida como tal en 1929 en concurso organizado por el periódico $A B C$, había comenzado su "carrera" hacia el título en concursos locales organizados por la prensa valenciana. No parece exagerado, pues, afirmar que el concurso de bellezas de la Exposición es precedente inmediato de los grandes concursos de misses y que el hecho de que dos valencianas ganasen los dos primeros concursos de Miss España (la segunda, en 1930, fue Elena Pla) parece indicativo del arraigo de este tipo de concursos en territorio valenciano.

La Exposición aderezó sus perspectivas turísticas, vinculadas a la "tierra de las flores y de la alegría" -los eslóganes que se incorporaban a la "venta" de la urbe al visitantes-, con una Batalla de Flores inaugural, en la que las carrozas principales fueron elaboradas por artistas famosos -la carroza del rey fue elaborada por los artitas Fillol, Causarás, Mollá y Badía-. Veladas alegres vinculadas al baile y a la verbena se sucedían. Los juegos infantiles en la Pista de la Exposición se combinaron con la producción industrial del ocio cuando en la pista se colocaron los "fuegos japoneses" importados por la casa Broock de Londres: "cuatro cañones de metal; los pirotécnicos encienden los estopines, y de las bocas de aquellos salen con una detonación formidable, grandes bombas que, en lo alto, se desgranan en lluvia de juguetes" (Valencia, 8/8/09).

El recinto de la Exposición contaba con un Teatro-Circo en el que se programaron desde compañías de acróbatas hasta sesiones de zarzuela, pasando por el espectáculo que por entonces hacía furor: las variedades. Sin embargo, la tensión entre las pretensiones de los programadores y los gustos populares se hizo muy evidente en este terreno. En el teatro y en la pista se programó mucha música, pero sobre todo de banda y orquesta, así como de orfeón. En alguna ocasión, los bailes regionales complementaban este tipo de espectáculos. Por otra parte, la Exposición coincidía en su desarrollo con el Certamen Musical que desde principios de siglo organizaba la ciudad de Valencia y que tenía la música de banda como motivo. Ese año fue un verdadero desastre: se inscribieron menos bandas que en los años anteriores, siendo paupérrima la participación y la banda invitada, la Municipal de Madrid, tuvo la desgracia de que falleciese uno de sus músicos de forma repentina, lo cual la obligó a suspender varios conciertos.

\subsection{Foro de congresos}

Hoy el "turismo de congresos" es una especialidad en la rama general de actividad del turismo. En cuanto foro de reuniones de asociaciones, la Exposición Regional reunió el V Congreso Nacional de Arquitectos, la Segunda Asamblea Reformista de Instrucción Nacional, el Congreso Regional de Económicas de Amigos del País, el Congreso Nacional de Pedagogía, el de Esperantistas al que acudió el mismísimo doctor Zamenhof, el Congreso Nacional de Contadores Peritos y Profesores Mercantiles presidido por Basilio Paraíso, el Congreso de Secretarios 
de Ayuntamiento, el Congreso Penitenciario organizado por el criminalista Emilio Borso di Carminati, la Asamblea de las Cámaras de Comercio, el Congreso de Médicos Titulares, el Nacional de Reformas Sociales, la Asamblea Farmacéutica, el Congreso Agrario Nacional o la Asamblea Forestal. Evidentemente, los participantes en los congresos y asambleas, con sus familias en muchos casos, fueron un nutriente básico en la cifra de visitantes de la Exposición. Eran, en cierto modo, su público cautivo.

También para ensayar algunas de las estrategias turísticas que parecían amagar tras la Exposición: el turismo urbano acompañado con el excursionismo paisajístico y de "antigüedades". El castillo de Sagunto, distante unos 25 kilómetros de la ciudad, fue por ejemplo visita obligada en las excursiones de los congresistas y hasta una de ellas, la de los esperantistas, sufrió un accidente al caerse un paño del muro almenado. Unos años antes, Aloïs Riegl (2007, original de 1903), presidente de la vienesa Comisión de Monumentos Históricos, había explicado que el valor de los monumentos no se agotaba en absoluto en su valor histórico-artístico, ni siquiera en su valor rememorativo: existía un pujante "valor de antigüedad" en el que se regodeaba el hombre moderno por ser exponente del "ciclo natural de creación y destrucción", por construir el paralelismo entre la erosión del monumento por parte de la naturaleza y el paso del tiempo sobre la propia vitalidad del hombre. El valor de antigüedad, a diferencia del histórico-artístico, era fácil de distinguir: no hacía falta ser un connaisseur. Sólo comprobar los efectos del tiempo sobre la obra humana intencional. Por eso era el valor del turismo de masas vinculado a los monumentos.

\section{EXPOSICIÓN: ENTRE LOS RESULTADOS INTANGIBLES Y LOS VALORES SIMBÓLICOS}

En paralelo a la Exposición, apareció la revista Valencia. Literatura, Arte, Actualidades, cuyo primer número, de 20 de mayo de 1909, fue prólogo a la inauguración realizada dos días después. Quincenal y vendida a 20 céntimos en ejemplar, la publicación pretendía realizar la crónica encomiástica de los diferentes eventos que se iban a suceder en la Exposición. Y así fue.

A la par, también muy imbuida del espíritu turístico que rodeó a la Exposición, ofreció algunos reportajes de las atracciones valencianas, entre los que cabe destacar alguno muy extenso sobre sus playas. Al fin y al cabo, los baños de mar habían generado ya un cierto negocio desde mediados del siglo XIX y resultaban un ariete potencial en el desarrollo turístico (Walton, 2001). La revista, sin embargo, no cruzó el Rubicón de la conversión de la Exposición Regional en Nacional, en prueba más que evidente de que el proyecto era sobrevenido, mero producto del enorme déficit económico acumulado.

$\mathrm{Si}$ algo denotan las muchas fotografías de la revista Valencia es que la Exposición mantuvo siempre un aire aristocrático que, al parecer, nunca llegó a compadecerse bien con los contenidos interclasistas y populares que exigían 
los nuevos espectáculos masivos. De hecho, incluso los elementos a priori populares de la Exposición -como los bailes regionales, el ciclismo, el fútbol o el atletismo- fueron planteados para la observación de los más pudientes, pero no para concitar el concurso general de las diferentes clases sociales de la Valencia de la época. Tal vez esta sea una razón, que no la única, por la que las cifras de visitantes no colmaron las previsiones.

Desde luego, otro factor adicional y ya comentado, fue la incompatibilidad entre la escasa oferta de alojamiento y de transporte con un acontecimiento pensado como masivo.

Con todo, Settier y su Secretaría de Propaganda consiguieron eco en la prensa local, española y francesa. Menor del esperado. Contra sus vaticinios, el teórico mejor momento de la Exposición, pasados los calores del verano de 1909, resultó ser el peor (AHCCINV, leg. H-187/17). El "ruido" informativo generado por acontecimientos de extraordinaria gravedad -a los que ni siquiera pudo sustraerse la revista Valencia-, como la guerra en el norte de África o las revueltas sociales en Barcelona y otros lugares (Semana Trágica), pusieron sordina a los ecos de la estrategia propagandística de la Exposición Regional.

¿Qué había detrás de la Exposición? En este trabajo se ha visto que un intento por poner a Valencia en el disparadero de una nueva industria: el turismo. Y, en este aspecto, el éxito no sobrevino. Al menos a corto plazo.

Pero había más. La otra agenda. Trenor, hombre de fortuna, era uno de los más influyentes elementos del Partido Conservador valenciano. La revista Valencia, editada por la misma empresa de Las Provincias, el periódico conservador de la ciudad, se dedicó a ensalzar la figura de Teodoro Llorente, durante mucho tiempo hombre imprescindible en los cargos orgánicos de ese mismo Partido Conservador. Se diría que, más allá de las habituales prácticas caciquiles tan propias de los partidos del turno, el conservadurismo ensayaba nuevas estrategias discursivas que pretendían crear identidad, valenciana y conservadora, solapándose con el nuevo "negocio de los forasteros".

En la práctica totalidad de actos desarrollados durante la Exposición sonó su Himno oficial, creación del maestro Serrano que, aunque devendrá Himno Regional a finales de la década de 1920, ya por entonces era referido por la prensa como Himno de Valencia. Parecía existir una propensión simbólica, esto es, hacia la creación de elementos simbólicos de identificación de los valencianos tras los propósitos de los organizadores de la Exposición.

Valencia era la ciudad republicana de España; la ciudad de Blasco Ibáñez y del blasquismo; la ciudad de Soriano y el sorianismo; la ciudad en la que los partidos del turno restauracionista, liberales y conservadores, habían quedado hechos añicos y sólo una Liga Católica, auspiciada con recursos populistas, suma de viejos legitimismos y nuevas doctrinas social-católicas, hacía frente a la movilización de masas conseguida por los republicanos; éstos, a su vez, estaban divididos, como por doquier; aquí entre blasquistas y sorianistas, 
siempre con liderazgos fuertes e irreconciliables, siempre con matices separadores.

En todo caso, los organizadores de la exposición representaban a la "aristocracia" vencida en las urnas de la ciudad; la "aristocracia" de la vieja política restauracionista. Tomás Trenor, el gran fautor, era, como se dijo, hombre del Partido Conservador. Sus adláteres en el Comité Ejecutivo o eran de su misma filiación, o eran monárquicos de significación liberal.

El gran homenaje de la Exposición se realizó en honor de Teodoro Llorente, el gran vate local, el "poeta de Valencia", nacido en 1836 y que fallecería en 1911. Pero haríamos mal en no recordar que Llorente era jefe del Partido Conservador y que el periodista que había impulsado inicialmente el homenaje, un discípulo suyo, Vicente Calvo Acacio, militaba en el Partido Liberal. El rey y la familia real eran las "estrellas" -hoy diríamos mediáticas- de la Exposición. En la revista Valencia la primera fotografía era la del por entonces presidente del gobierno, el conservador Antonio Maura.

Algo no encajaba. Los latinos decían: locus riget actum. $\mathrm{Y}$ no era así. Los "viejos políticos" del turno parecían querer congraciarse con los habitantes de su ciudad, dándoles un gran evento y una nueva industria del ocio. Para ello sobrecargaron los elementos simbólicos -himnos, folclore- y propagandísticos, pero no intuyeron que la contradicción más palmaria les estallaría en las manos: decididos belicistas a partir de 1909, muchos de ellos con intereses directos en Marruecos o en Guinea, su propio negocio no era el turismo, sino la inversión de capitales allí donde éstos iban a deparar buenos rendimientos, aunque costase embarcar unos cuantos miles de soldados para allanar un Protectorado y múltiples negocios (Martínez, Chust y Hernández, 2001).

Y los soldados eran parte de ese público popular que la Exposición convocaba. El himno les pedía "ofrendar nuevas glorias a España". Tal vez alguien pensó a principios de 1909 que las glorias tenían forma de trabajo en el taller o en la huerta. Pero a partir del verano de ese mismo año, las glorias eran de otra naturaleza: militares, patrióticas, por muchos traducidas como un ejército de gente pobre haciéndole el trabajo sucio a los inversores. Y bajo las condiciones de siempre: con la quinta odiada como mecanismo de conscripción, con sus sustituciones y sus redenciones.

Las clases populares de Valencia se dieron de bruces con estas "glorias" en el verano de 1909 y esto hundió a la Exposición. De hecho, su conversión en Exposición Nacional en 1910 obedeció a un intento de salvar el maltrecho balance, especialmente económico, de la misma. Sólo sirvió para empeorarlo.

La Exposición Regional de Valencia resultó, pues, una experiencia innovadora en cuanto a la promoción turística a través de la publicidad comercial, pero cayó en el error de no medir la influencia de las infraestructuras que rodean a un "gran acontecimiento" y que resultan de primer orden de importancia para la afluencia del público. Los graves acontecimientos políticos sobrevenidos hicieron el resto. 
Los inversores que se habían situado tras la organización de la Exposición -empezando por el propio Trenor y siguiendo por Ramón e Castro, presidente de la Cámara de Comercio- dirigieron sus capitales no al turismo, sino a otro tipo de negocios, por cierto, muchos relacionados con las inversiones en las colonias de Guinea o en el Protectorado de Marruecos.

El "negocio de los forasteros" quedó vinculado a algunas iniciativas locales, voluntaristas pero de escaso vuelo. En 1906 había aparecido en la localidad alicantina de Denia la sociedad El Clima, "dedicada a ejercer una activa propaganda de las grandes condiciones que tiene aquella preciosa ciudad para la estación invernal" (El Correo, 16/2/1906). En 1915 nació en Requena la Sociedad Requenense de Iniciativas (Requena Veraniega, $\left.n^{\circ} 1,28 / 8 / 1915\right)$, que promovía lo que hoy llamamos turismo de interior en contraposición al de sol y playa.

Hasta 1919 no se fundó en Valencia un nuevo Sindicato de Iniciativa, la Sociedad Valenciana para el Fomento del Turismo (Bigné, 2006). Habían pasado diez años desde la Exposición Regional. La guerra de Marruecos, con sus vaivenes, seguía en marcha. Pero la Guerra Mundial había terminado, tras generar grandes beneficios entre los exportadores de una economía muy volcada hacia el comercio exterior como la valenciana. Sólo entonces los capitales fluyeron hacia el nuevo sector, paulatinamente.

La otra agenda, la que hoy llamaríamos propiamente propagandística de la Exposición, también fracasó en el corto plazo. El Partido Conservador, en general la opción monárquica, no consiguió, ni remotamente, reconquistar la hegemonía política. Valencia tuvo alcaldes conservadores mientras lo fueron por designación; cuando se estableció, a partir de 1917, la elección democrática de la primera autoridad local, sus alcaldes fueron republicanos.

\section{REFERENCIAS BIBLIOGRÁFICAS}

ADV: ARCHIVO DE LA DIPUTACIÓN DE VALENCIA.

AMENGUAL, B. (1993): La Industria de los forasteros. Facsímil del original de 1903. Palma de Mallorca: Miquel Font.

AHCCINV: ARCHIVO HISTÓRICO DE LA CÁMARA DE COMERCIO, INDUSTRIA Y NAVEGACIÓN DE VALENCIA legajos $\mathrm{H}-187 /$ 07, 08, 17.

BARJAU, S.: "Los inicios del pensamiento publicitario: Pere Prat Gaballí, Rafael Borí y el Publi Club. La teoría y la práctica de la publicidad racional en Cataluña entre 1915 y 1939", Publifilia, nº (2002), pp. 89-105.

BAYON, F.; y FERNÁNDEZ, L.: Los orígenes. En AA.VV. (2005): 50 años del turismo español. Un análisis histórico y estructural. Madrid: Editorial Centro de Estudios Ramón Areces S.A., pp. 25-44.

BERNAYS, E. (2008): Propaganda. Barcelona: Melusina. 
BLANCO GARCÍA, J. (2007): Historia de las Exposiciones Internacionales (Londres 1851Zaragoza 1908). Zaragoza: Editorial Delsan.

BIGNÉ ALCAÑIZ, J.E.: El turismo en la economía valenciana. Un siglo de iniciativas. En AA.VV. (2006): De la Exposición Regional a la Copa América. Economía valenciana en el siglo XX. Valencia: Cámara Oficial de Comercio, Industria y Navegación de Valencia.

BOIRA, J.V.: La Exposición Regional de 1909. Un alarde de riqueza económica y de vitalidad regionalista valenciana. En AA.VV. (2009): Economía, empresa y sociedad. La Exposición Regional Valenciana de 1909. Valencia: Cámara Oficial de Comercio, Industria y Navegación de Valencia, pp. 40-69.

CAL, R.: "La propaganda del turismo en España. Primeras organizaciones", Historia y Comunicación Social, n² 2 (1997), pp. 125-133.

CONGRESO DE LA ASOCIACIÓN ESPAÑOLA PARA EL PROGRESO DE LAS CIENCIAS, II (1909): Guía de Valencia. Valencia: Impr. F. Vives Mora.

CORREDERO, B.; y CAL, R. (2008): Turismo: la mayor propaganda de Estado. España desde los orígenes hasta 1951. Madrid: Visión Libros.

DUGAST, J. (2003): La vida cultural en Europa entre los siglos XIX y XX. Barcelona: Paidós.

ERICE, F.: Entre la represión y el paternalismo. Actitudes burguesas ante 'lo popular' en la España de la Restauración. En URÍA, J. (2003): La cultura popular en la España contemporánea. Doce estudios. Madrid: Biblioteca Nueva, pp. 131-152.

GIL SALINAS, R.; y MILLÁN, M.J.: La Exposición Valenciana de 1909. El espectáculo de la modernidad o la modernidad como espectáculo. En AA.VV. (2009): El Ateneo Mercantil y la Exposición valenciana de 1900. Valencia: Ateneo Mercantil.

GONZÁLEZ MORALES, J.C.: "La Comisión Nacional de Turismo y primeras iniciativas para el fomento del turismo: la industria de los forasteros (1905-1911)", Estudios Turísticos, n ${ }^{\circ}$ 163-164 (2005), pp. 17-30.

MARTÍNEZ GALLEGO, F.A. (1995): Desarrollo y crecimiento: la industrialización valenciana, 1834-1914. Valencia: Conselleria d'Indústria, Comerç i Turisme.

MARTíNEZ GALLEGO, F.A.; CHUST, M.; y HERNÁNDEZ, E. (2001): Valencia, 1900: movimientos sociales y conflictos políticos durante la guerra de Marruecos, 1906-1914. Castellón: Servicio de Publicaciones de la Universidad Jaume I.

MARTÍNEZ GALLEGO, F.A.; y LAGUNA, A.: La gestión menguante: entre la estabilidad administrativa y el fracaso autonomista (1902-1923). En CHUST, M. (ed.) (1995): Historia de la Diputación de Valencia. Valencia: Diputación de Valencia.

MONTANER MONTEJANO, J. (1998): Diccionario de Turismo. Madrid: Síntesis.

MORENO GARRIDO, A. (2007): Historia del turismo en España en el siglo XX. Madrid: Síntesis.

OBIOL MENERO, E.M.: “Las 'Guías de Valencia' (1840-1930). Notas para un análisis turístico", Cuadernos de Geografía, n 65-66 (1999), pp. 255-265.

PAMPLONA ESCUDERO, R. (1908): Libro de oro. Exposición Hispano-Francesa de 1908; Zaragoza. Zaragoza: Revista Aragonesa. 
PINEDA, A. (2006): Elementos para una teoría comunicacional de la propaganda. Sevilla: Alfar.

RIEGL, A. (2007): El culto moderno a los monumentos. Madrid: A. Machado Libros S.A. Edición original de 1903.

SERNA, J.; y PONS, A.: Los viajes interiores. Las bibliotecas burguesas de la Valencia del Ochocientos. En MONTIEL, G.; y MARTíNEZ, E. (eds.) (2004): Viajar para saber. Movilidad y comunicación entre universidades europeas. Valencia: PUV, pp. 267-297.

SIRERA, C. (2008): Cuando el fútbol no era el deporte rey. Los deportes en el espacio público de la ciudad de Valencia (1875-1909). Valencia: PUV.

TEIXIDOR DE OTTRO, M.J.; y HERNÁNDEZ SORIANO, T. (2000): La Fábrica de Tabacos de Valencia. Valencia: PUV.

TRENOR PALAVICINO, T. (1912): Memoria de las Exposiciones Regional Valenciana de 1909 y Nacional de 1910. Valencia: s/e.

URÍA, J.: Cultura popular y actividades recreativas: la Restauración. En URÍA, J. (2003): La cultura popular en la España contemporánea. Doce estudios. Madrid: Biblioteca Nueva, pp. 77-108.

VEGAS, F. (2003): La arquitectura de la Exposición Regional Valenciana de 1909 y de la Exposición Nacional de 1910. Valencia: Universidad Politécnica de Valencia.

VIDAL CASELLAS, D. (2005): L'imaginari monumental $i$ artístic del turisme cultural. El cas de la revista 'Barcelona Atracción'. Girona: Universidad de Girona. Tesis doctoral inédita.

VILAR, J.B. (1975): Emigración española a Argelia (1830-1900). Madrid: Instituto de Estudios Africanos.

WALTON, J.K.: Consuming the beach: seaside resorts and cultures of tourism in England and Spain from the 1840s to the 1930s. En FURLOUGH, E.; y BARANOWSKI, S. (ed.) (2001): Being elsewhere: tourism, consumer culture and identity in modern Europe and North America. Ann Arbor: University of Michigan Press, pp. 272-298.

\section{Breve semblanza biográfica del autor}

Francesc-Andreu Martínez Gallego es Profesor Titular del Área de Periodismo de la Universidad de Valencia. Su trabajo se ha orientado a la historia de la comunicación y en ese campo ha publicado, con A. Laguna y E. Bordería, Historia de la Comunicación Social. Voces, registros y conciencias (Madrid, Síntesis, 1996) y diversas monografías. También se interesa por la economía política y la estructura de los medios y ha participado en el libro colectivo, editado por Guillermo López, El ecosistema comunicativo valenciano. Características y tendencias en la primera década del siglo XXI (Valencia, Tirant lo Blanch, 2010). Su último libro, que edita con J.L. Gómez Mompart y E. Bordería es La risa periodística. Teoría, metodología e investigación en comunicación satírica (Valencia, Tirant lo Blanch, 2010). 